\title{
Does NPH equal ischemia?
}

\section{Gerald Silverberg*1,2, Conrad Johanson², John Duncan², Thomas Brinker ${ }^{3}$, Stephanie Slone ${ }^{2}$, Arthur Messier ${ }^{2}$, Sarah Soltman ${ }^{2}$ and Petra Klinge ${ }^{3}$}

\author{
Address: 'Department of Neurosurgery, Stanford University, Stanford, CA 94305, USA, 2Department of Clinical Neuroscience, Brown University, \\ Providence, RI 02903, USA and ${ }^{3}$ Department of Neurosurgery, International Neuroscience Institute, Hanover 30625, Germany \\ Email: Gerald Silverberg* - geralds@stanford.edu \\ * Corresponding author
}

from $\left.5\right|^{\text {st }}$ Annual Meeting of the Society for Research into Hydrocephalus and Spina Bifida Heidelberg, Germany. 27-30 June 2007

Published: 20 December 2007

Cerebrospinal Fluid Research 2007, 4(Suppl I):S3 doi:I0.I I86/I743-8454-4-SI-S3

This abstract is available from: http://www.cerebrospinalfluidresearch.com/content/4/SI/S3

(c) 2007 Silverberg et al; licensee BioMed Central Ltd.

\section{Background}

It has been postulated that NPH equals pressure- and distortion-induced ischemia. Such a postulate fails to take into consideration the high co-incidence of $\mathrm{AD}$ and cerebrovascular disease (CVD) with NPH; as well as the observation that ischemia persists despite resolution of the elevated CSFP and ventriculomegaly [1,2]. We offer an alternate postulate, that NPH is a multi-factorial disease and that defective metabolite clearance, e.g., amyloid-beta peptides (A $\beta$ ) and Tau protein, via the CSF and across the blood-brain barrier (BBB), play a significant role in the dementia and ischemia of NPH.

\section{Materials and methods}

Aged Sprague-Dawley rats (12 mos) had hydrocephalus induced by intracisternal kaolin injection [3]. Brains were harvested at two, six and 10 weeks post-induction, $n=4-$ 6 for each experimental group. The brains were stained for $\mathrm{A} \beta$, hyperphosphorylated Tau (hpTau), and the A $\beta$ transporters LRP-1, Pgp and RAGE (receptor for advanced glycation end products) by immunohistochemistry (IHC). Three epitopes of hpTau were used: pT231, pS262 (intraneuronal) and AT100 (extraneuronal). Cerebral microvessel isolations (MVIs) were performed and the extracted RNA and protein were assayed for the A $\beta$ transport proteins. Western blots and ELISA were used to assay A $\beta$ and Tau accumulation. Aged matched non-operated rats serves as controls.

\section{Results}

On IHC, A $\beta$ accumulated in cortex and hippocampus with increasing hydrocephalus, particularly around microvessels and in and around neurons. HpTau, pT231, was seen in neurons in a typical AD pattern: loss of dendritic hpTau and accumulation and margination of hpTau granules in the cell soma. Extracellular hpTau, AT100, was also seen to accumulate around blood vessels. The $A \beta$ transport proteins were significantly altered in the MVIs compared to controls: LRP-1 and Pgp were down-regulated whereas RAGE was up-regulated.

\section{Conclusion}

These studies show that induction of hydrocephalus (increased resistance to CSF absorption and decreased CSF production and turnover) leads to defective CSF and BBB metabolite clearance, and to the accumulation of $A \beta$ and hpTau, similar to what is seen in AD [4,5]. The localization of $A \beta$, a known vasoconstrictor, and hpTau to cerebral blood vessels suggests that these toxins may play a role in the persistent ischemia and CVD seen in NPH. Hydrocephalus in aged animals, therefore, causes severe metabolic dysfunction, due to a progressive inability to clear metabolites, and is likely a major cause of the pathology in NPH.

\section{References}

I. Golomb J, Wisoff J, Miller DC, Boksay I, Kluger A, Weiner H, Salton J, Graves W: Alzheimer's disease comorbidity in normal pressure hydrocephalus: Prevalence and shunt response. J Neurol Neurosurg Psychiat 2000, 68:778-78I. 
2. Momjian S, Owler BK, Czosnyka Z, Czosnyka M, Pena A, Pickard JD: Pattern of white matter regional cerebral blood flow and autoregulation in normal pressure hydrocephalus. Brain 2004, I 27:965-972.

3. Klinge PM, Samii A, Muhlendyck A, Visnyei K, Meyer G-J, Walter GF, Silverberg GD, Brinker T: Cerebral hypoperfusion and delayed hippocampal response after induction of adult kaolin hydrocephalus. Stroke 2003, 34:193-199.

4. Augustinack JC, Schneider A, Mandelkow E-M, Hyman BT: Specific tau phosphorylation sites correlate with severity of neuronal cytopathology in Alzheimer's disease. Acta Neuropathol 2002, 103:26-35.

5. Donahue JE, Flaherty SL, Johanson CE, Duncan JA III, Silverberg GD, Miller MC, Tavares R, Yang W, Wu Q, Sabo E, Hovanesian V, Stopa EG: RAGE, LRP-I, and amyloid-beta protein in Alzheimer's disease. Acta Neuropathol 2006, I I 2:405-4I5.

Publish with Bio Med Central and every scientist can read your work free of charge

"BioMed Central will be the most significant development for disseminating the results of biomedical research in our lifetime. "

Sir Paul Nurse, Cancer Research UK

Your research papers will be:

- available free of charge to the entire biomedical community

- peer reviewed and published immediately upon acceptance

- cited in PubMed and archived on PubMed Central

- yours - you keep the copyright

Submit your manuscript here:

http://www.biomedcentral.com/info/publishing_adv.asp 